\title{
Lower Extremities Symmetry-Asymmetry Indices Dependence on the Parameters of Motor- Coordinating Abilities Among People Going in for Impact Single Combats
}

\author{
Eganov A.V. \\ Ural State University of Physical Culture \\ Chelyabinsk, Russia \\ eganov@bk.ru
}

\author{
Bykov V.S. \\ South-Ural State University (national research University \\ Chelyabinsk, Russia \\ fiss-bikov@mail.ru
}

\author{
Kolunin E.T. \\ Tyumen State University \\ Tyumen, Russia \\ e.t.kolunin@utmn.ru
}

\begin{abstract}
Correlation matrix structure analysis of the separate lower extremities symmetry-asymmetry indices with the parameters of motor-coordinating abilities (MCA), among people going in for impact single combats, showed the differences in connections orientation, the level of their demonstration and also their amount. With MCA parameters the preference to kick with the right lower extremity has three connections, the preference to kick with both lower extremities has 7 connections, the preference to kick with the left lower extremity has 4 connections. Sportsmanship is connected with the preference to kick with the left lower extremity, the level of general and special MCA, integral motor action coordination, quickness of reaction to the opponent's movement, dynamic strength-oriented characteristics of the movement, foot motor activity, integral MCA index. The parameter of preference to kick using both lower extremities is provided by the level of MCA development.
\end{abstract}

Keywords-symmetry-asymmetry; lower extremities; coordination; correlation; impact single combats.

\section{INTRODUCTION}

Contemporary state of the problem of athletes' lower extremities motor symmetry-asymmetry, which are demonstrated in impact single combats in the structure of readiness and the peculiarities of the mechanisms of its realization in a combat demands special study. The necessity to take into account motor symmetry-asymmetry of lower extremities is the reserve for sports qualification improvement $[3,4,11]$. The increased interest in the questions of motor asymmetry is extremely urgent in sport $[1,6,10,11]$. However, there is no clear information concerning symmetryasymmetry of lower extremities. System approach during "symmetry-asymmetry" problems solution helps to get new facts concerning their functioning among athletes [7].

\section{LITERATURE REVIEW}

The effectiveness and reliability of technical actions depend on the separate motor-coordinating abilities development: spatial characteristics (trajectory, direction, amplitude of movement), motor activity correspondence in "hand-leg" system, distinctive sensitivity (in time, space, dynamic efforts differentiation), balance, extrapolation, which define the character of motor activity $[3,4,8,9]$.

The reason for motor asymmetry is different function of the right and the left hemispheres in a system activity of the brain in movements controlling of extremities and conditions of a person's life. It is obvious that the training process influences the degree of asymmetry and is connected with coordinating readiness [9].

Using correlation analysis method V.A. Eganov, V.S. Bykov revealed valid dependence between the ability of a kickboxer to kick with both lower extremities and the level of sportsmanship. In the opinion of the authors, sports result is conditioned by the ambidexterity of kickboxers in lower extremities and the training process should be directed toward motor asymmetry overcoming [4].

In the opinion of G.P. Ivanova and other authors [5], one of the reasons for asymmetry is mass center distribution in the body of a person during vertical pose in frontal plane relative to its direct axis. Symmetric body masses should be considered as a particular case of asymmetry. Stationary foot, which corresponds with the direction of body shift in frontal plane would experience great load. Non- stationary foot doesn't have great loads in this case and becomes less adapted to any actions fulfillment.

In each motor action both legs are the leading, however, they fulfill different functions. In kicking weight shift from the stationary leg to non-stationary one and vice versa are unequal in coordination. As asymmetry of legs work is the most important factor of muscle groups coordination [5]. During a kick the left leg among right-handed people in most cases is stationary and the right leg is swinging. It proves the 
dependence of functions distribution between legs and body movements coordination [6].

\section{RESEARCH METHODOLOGY}

The material is received during the period since 2015 till 2019 in Chelyabinsk. People, who go in for impact single combats were studied (Tae Kwon Do, thai boxing, kiokusinkay, boxing, sports karate, jujitsu, kick-boxing, handto-hand fighting, mixed martial arts). Symmetry-asymmetry of lower extremities study among athletes was held according to 6-point scale of subjective estimation. Sportsmanship was estimated according to 100-point scale [2]. 165 athletes took part in testing (among them 28 women, the average height $175,0 \mathrm{~cm}$, age $-21,2$ years-old, experience of training 8,5 years, go in for sports kinds of single combats).

The results of the stating stage were calculated by means of pair correlation coefficients determination (r) K. Pearson, which define the structure, direction of lower extremities motor symmetry-asymmetry indices connection with their further pedagogical interpretation. In case of positive correlation coefficient of the index the connection will be direct, which means that one index of the sampling increase lead to the other index increase. If the coefficient is negative the connection will be converse, which means that in case of one index increase there will be another index decrease. Such regularities revelation helps to understand cause-effect relations of the studied variables. The calculations were held using Microsoft Excel.

In accordance with the content of the article we consider it necessary to give the definition to some notions, how we understand them in this work.

Motor symmetry-asymmetry of athletes' lower extremities is understood as the opposition of two parts of the whole with the division into two non-crossing planes. In the work motor symmetry-asymmetry of lower extremities is considered relative to sagittal plane, which "divides" body into the right and the left parts and transversal plane, which "divides" body into the upper and the lower parts, providing sports activity analysis. For example, the preferable use of the kicks with the right, left, both legs. Symmetry-asymmetry of lower extremities is considered as the sign of genetically fixed form of physiological differences of brain functions or directed long-term methodology of sports training.

Asymmetry of lower extremity function is understood as dominant participation of one of them in the process of sports activity in terms of equally possible choice between them.

An integral index of motor-coordinating abilities (MCA) is a sum of the separate parameters, which characterize the ability to achieve accuracy, timeliness, order, transformation, adaption to movements and etc., in points.

\section{RESULTS}

Correlation structure of MCA parameters of lower extremities, which are demonstrated in the combat by the example of sports impact single combats, is presented in table 1 , in a form of a matrix of the $13^{\text {th }}$ order.
Index 9 - preference to kick with the right lower extremity, has valid positive dependencies with indices 4, 6, 8: quickness of reaction to the movements of the opponent, timeliness and movements adequacy, integral MCA index and in negative (converse) dependencies with the index preference to kick in the combat with the left lower extremity, index 11. Pedagogical essence of the revealed dependencies means that athletes' inclination to kick with the right lower extremity is connected with high level of quickness of reaction development to the opponent's movements, with timeliness and adequacy of movements and integral MCA index.

TABLE I. CORRELATION STRUCTURE OF MCA PARAMETERS OF

LOWER EXTREMITIES, WHICH ARE DEMONSTRATED IN THE OMBAT BY THE EXAMPLE OF SPORTS IMPACT SINGLE COMBATS

\begin{tabular}{|c|c|c|c|c|c|c|c|c|c|c|c|c|c|}
\hline Parameters and indices & 1 & 2 & 3 & 4 & 5 & 6 & 7 & 8 & 9 & $\begin{array}{l}1 \\
0\end{array}$ & $\begin{array}{l}1 \\
1\end{array}$ & $\begin{array}{l}1 \\
2\end{array}$ & $\begin{array}{l}1 \\
3\end{array}$ \\
\hline 1 General MCA & 1 & & & & & & & & & & & & \\
\hline 2 Special MCA & $\begin{array}{l}5 \\
2 \\
\end{array}$ & 1 & & & & & & & & & & & \\
\hline $\begin{array}{l}3 \text { Consistency of the } \\
\text { integral motor action }\end{array}$ & $\begin{array}{l}3 \\
8 \\
\end{array}$ & $\begin{array}{l}3 \\
9 \\
\end{array}$ & 1 & & & & & & & & & & \\
\hline $\begin{array}{l}4 \text { Quickness of } \\
\text { reaction to the } \\
\text { opponent's } \\
\text { movements }\end{array}$ & $\begin{array}{l}4 \\
3 \\
\end{array}$ & $\begin{array}{l}5 \\
4 \\
\end{array}$ & $\begin{array}{l}3 \\
7 \\
\end{array}$ & 1 & & & & & & & & & \\
\hline $\begin{array}{l}5 \text { Dynamic power } \\
\text { characteristics of } \\
\text { movement }\end{array}$ & $\begin{array}{l}3 \\
8 \\
\end{array}$ & $\begin{array}{l}3 \\
5\end{array}$ & $\begin{array}{l}2 \\
8 \\
\end{array}$ & $\begin{array}{l}3 \\
9 \\
\end{array}$ & 1 & & & & & & & & \\
\hline $\begin{array}{l}\text { 6. Timeliness and } \\
\text { adequacy of } \\
\text { movements }\end{array}$ & $\begin{array}{l}3 \\
7 \\
\end{array}$ & $\begin{array}{l}4 \\
9 \\
\end{array}$ & $\begin{array}{l}4 \\
9 \\
\end{array}$ & $\begin{array}{l}5 \\
2 \\
\end{array}$ & $\begin{array}{l}3 \\
8 \\
\end{array}$ & 1 & & & & & & & \\
\hline $\begin{array}{l}\text { 7. Motor activity of } \\
\text { lower extremity foot }\end{array}$ & $\begin{array}{l}3 \\
1 \\
\end{array}$ & $\begin{array}{l}3 \\
9 \\
\end{array}$ & $\begin{array}{l}2 \\
8 \\
\end{array}$ & $\begin{array}{l}3 \\
5 \\
\end{array}$ & $\begin{array}{l}4 \\
8 \\
\end{array}$ & $\begin{array}{l}5 \\
0\end{array}$ & 1 & & & & & & \\
\hline $\begin{array}{l}8 \text { Integral index of } \\
\text { MCA }\end{array}$ & $\begin{array}{l}5 \\
5\end{array}$ & $\begin{array}{l}6 \\
1\end{array}$ & $\begin{array}{l}5 \\
8 \\
\end{array}$ & $\begin{array}{l}6 \\
6 \\
\end{array}$ & $\begin{array}{l}6 \\
2 \\
\end{array}$ & $\begin{array}{l}6 \\
8 \\
\end{array}$ & $\begin{array}{l}6 \\
6 \\
\end{array}$ & 1 & & & & & \\
\hline $\begin{array}{l}\text { 9.Preference to kick } \\
\text { with the right lower } \\
\text { extremity }\end{array}$ & $\begin{array}{l}0 \\
0 \\
\end{array}$ & $\begin{array}{l}1 \\
1 \\
\end{array}$ & $\begin{array}{l}0 \\
8\end{array}$ & $\begin{array}{l}1 \\
9\end{array}$ & $\begin{array}{l}0 \\
5\end{array}$ & $\begin{array}{l}1 \\
6 \\
\end{array}$ & $\begin{array}{l}1 \\
1\end{array}$ & $\begin{array}{l}1 \\
7\end{array}$ & 1 & & & & \\
\hline $\begin{array}{l}\text { 10. Preference to kick } \\
\text { with both lower } \\
\text { extremities }\end{array}$ & $\begin{array}{l}1 \\
8\end{array}$ & $\begin{array}{l}\mathbf{2} \\
\mathbf{1} \\
\end{array}$ & $\begin{array}{l}2 \\
2 \\
\end{array}$ & $\begin{array}{l}2 \\
2\end{array}$ & $\begin{array}{l}0 \\
7 \\
\end{array}$ & $\begin{array}{l}2 \\
4 \\
\end{array}$ & $\begin{array}{l}3 \\
7 \\
\end{array}$ & $\begin{array}{l}3 \\
9 \\
\end{array}$ & $\begin{array}{l}1 \\
4 \\
\end{array}$ & 1 & & & \\
\hline $\begin{array}{l}\text { 11. Preference to kick } \\
\text { in the combat with the } \\
\text { left lower extremity }\end{array}$ & $\begin{array}{l}1 \\
4\end{array}$ & $\begin{array}{l}1 \\
0\end{array}$ & $\begin{array}{l}\mathbf{2} \\
\mathbf{0}\end{array}$ & $\begin{array}{l}0 \\
2\end{array}$ & $\begin{array}{l}0 \\
4\end{array}$ & $\begin{array}{l}1 \\
6\end{array}$ & $\begin{array}{l}2 \\
7\end{array}$ & $\begin{array}{l}1 \\
7\end{array}$ & $\begin{array}{l}- \\
4 \\
1\end{array}$ & $\begin{array}{l}4 \\
2\end{array}$ & 1 & & \\
\hline 12. Sportsmanship & $\mathbf{1}$ & $\begin{array}{l}\mathbf{2} \\
\mathbf{0}\end{array}$ & $\begin{array}{l}\mathbf{2} \\
\mathbf{5} \\
\end{array}$ & $\begin{array}{l}2 \\
2 \\
\end{array}$ & $\begin{array}{l}2 \\
6 \\
\end{array}$ & $\begin{array}{l}\mathbf{2} \\
\mathbf{0}\end{array}$ & $\begin{array}{l}1 \\
9\end{array}$ & $\begin{array}{l}\mathbf{2} \\
\mathbf{2} \\
\end{array}$ & $\begin{array}{l}0 \\
2 \\
\end{array}$ & $\begin{array}{l}0 \\
2 \\
\end{array}$ & $\begin{array}{l}\mathbf{1} \\
6 \\
\end{array}$ & 1 & \\
\hline $\begin{array}{l}13 \text { The age of athletes, } \\
\text { years }\end{array}$ & $\begin{array}{l}0 \\
6\end{array}$ & $\begin{array}{l}0 \\
8\end{array}$ & $\begin{array}{l}1 \\
4\end{array}$ & $\begin{array}{l}0 \\
1\end{array}$ & $\begin{array}{l}0 \\
6\end{array}$ & $\begin{array}{l}1 \\
1\end{array}$ & $\begin{array}{l}0 \\
6\end{array}$ & $\begin{array}{l}0 \\
5\end{array}$ & $\begin{array}{l}- \\
1 \\
1\end{array}$ & i & $\begin{array}{l}1 \\
7\end{array}$ & $\begin{array}{l}5 \\
2\end{array}$ & 1 \\
\hline
\end{tabular}

Index 10 - preference to kick with both lower extremities, characterizing ambidexterity of lower extremities, has valid positive dependencies with indices $1,2,3,4,6,7,8$ and negative dependencies with the age of athletes, index 11 . It means that if an athlete prefers to kick with both lower extremities, he has higher level of general and special MCA development, consistency of the integral motor action, quickness of reaction to the opponent's movements, timeliness and adequacy of movements, motor activity of foot and integral index of MCA. Presumably ambidexterity of lower extremities decreases with the age of athletes increase. The parameter of preference to kick with both lower extremities, in comparison with the intensity of right or left sided asymmetry of lower extremities is mainly provided by the level of MCA development. 
Index 11 - preference to kick in the combat with the left lower extremity has valid positive dependencies with MCA indices $-3,6,7,10$ : consistency of the integral motor action, timeliness and adequacy of movements, motor activity of a foot, preference to kick with both lower extremities. Negative dependencies are revealed with the preference to kick with the right lower extremity and the age of the athletes. The essence of the revealed dependencies is in the fact that if an athlete prefers to kick with the left lower extremity, he mainly has: consistency of the integral motor action, timeliness and adequacy of movements, motor activity of a foot, integral MCA index and less intensive are the preference to kick with the right lower extremity, supposedly owing to the preference increase to kick with the left lower extremity.

Index 12 - the level of sportsmanship had valid positive connections with the following indices: $1,2,3,4,5,6,7,8$, 11,13 . Pedagogical sense of the revealed dependencies proves that with sportsmanship improvement increases the level of: general and special MCA, consistency of the integral motor action, quickness of reaction to the opponent's movements, dynamic power characteristics of movement, timeliness and adequacy of movements, motor activity of a foot, integral index. Athletes more often prefer kicking with the left lower extremity.

\section{DISCUSSION}

Correlation matrix analysis helped to make a supposition that the structure of dependencies of the separate symmetryasymmetry indices of lower extremities with MCA parameters among those who go in for impact single combats has the differences: in connections orientation, the level of their demonstration and according to their quantity. For example, with MCA parameters the index of preference to kick with the right lower extremity has 3 connections, the preference to kick with both lower extremities has 7 connections, the preference to kick with the left lower extremity has 4 connections. Thus, the preference to kick with the right, left or both extremities is provided by different MCA parameters, each of parameters has specific influence on symmetry-asymmetry indices and sportsmanship.

\section{CONCLUSION}

The revealed dependency of symmetry-asymmetry indices of lower extremities, among those who go in for impact single combats, further will help to influence directly the indices, which are connected with sportsmanship. Thus, the revealed correlation structure contributes into the theory and practice of sports training.

\section{References}

[1] Berdichevskaya E.M., Gronskaya A.S., Bugaets Ya.E., Khachaturova I.E. Functional asymmetry in terms of effective activity provision in sport. Assymetry. 2007, vol. 1,1, pp. 62-64.

[2] Eganov A.V. Methodology of motor-coordinating abilities estimation, which are demonstrated in competitive combat, in the applied kinds of single combats: questionnaire for athletes. Chelyabinsk: UralSUPC. 2015,11 .

[3] Eganov A.V., Martemyanov Yu.G., Yanchik V.V., Khalabov A.O. Dependency of motor symmetry-asymmetry demonstration of pair extremities technical actions fulfillment on motor-coordinating abilities of those, who go in for the applied kinds of single combats. Modern knowledge intensive technologies. 2019, 2, pp. 168-173.

[4] Eganov V.A., Bykov V.S. Motor ambidexterity of lower extremities, revealed among students-kickboxers. Educational-upbringing process optimization in educational estbalishments of physical culture: XXV regional scientificmethodical conference. Chelyabinsk: UrealSUPC. 2015, pp. 55-56.

[5] Ivanova G.P., Spirodonova D.V., Sutina E.N. About the role of motor asymmetry of lower extremity in the dynamics of sports achievements. Theory and practice of physical culture. 2003, 1, pp. 62-63.

[6] Ilin E.P. About functiuonal asymmetry of legs. Theory and practice of physical culture. 1963, 1, pp. 22-25.

[7] Kozlov K.M., Samsonova A.V., Stepanov V.S. Dichotomy (symmetryasymmetry) of athletes' physical development. Theory and practice of physical culture. 2005, 4, pp. 24-26.

[8] Kolesnik I.S., Kuznetsov A.S., Petrov A.G. Theoretical and methodical substantiation of balance formation as one of the leading coordinations of boxers. Pedagogico-psychological and medico-biological problems of physical culture and sport. 2009, 2(11), pp. 1-8.

[9] Nazarenko L.D., Kolesnik I.S., Osipov D.A. Physiological basis of the system of sports training improvement among boxers. Pedagogicopsychological and medico-biological problems of physical culture and sport. 2017, vol. 12(4), pp. 169-177. DOI 10/14526/04 2017277.

[10] Sologub E. B., Fedorov V. V. Differentiated approach to technicaltactical training of boxers taking into account asymmetry factors in system activity of the brain during movements control. Means and methods of technical mastery of boxers development: collection of scinetific works; LSRIPC. Leningrade. 1987, pp. 32-39.

[11] Chemerchei O.A., Eganov A.V. Factorial structure of extremities motor dichotomy among athletes, who go in for the applied kinds of single combats. Pedagogico-psychological and medico-biological problems of physical culture and sport. 2017, vol. 12(2, pp. 225-234. DOI 10.14526/01 2017226 